\title{
The Significance of Soluble Molecules of Cellular Adhesion, Nitric Oxide Metabolites, and Endothelin-1 and Their Associations as Markers of Progression of Inflammation in COPD
}

DOI: $10.17691 / \mathrm{stm} 2017.9 .2 .13$

Received November 14, 2016

N.I. Kubysheva, DSc, Senior Researcher, Research Laboratory "Medical Informatics", Higher School of Information Technologies and Information Systems";

L.B. Postnikova, MD, DSc, Professor, Pulmonary Physician;

S.K. Soodaeva, MD, DSc, Professor, Head of the Laboratory of Clinical and Experimental Biophysics ${ }^{3}$; Professor, Department of Human Pathology, Institute of Professional Education;

V.V. Novikov, DSc, Professor, Director, Research Center for Molecular Biology and Biomedicine ${ }^{5}$;

S.V. Shumilova, PhD, Researcher, Research Center for Molecular Biology and Biomedicine;

E.S. Kasatova, PhD, Senior Researcher, Research Center for Molecular Biology and Biomedicine;

T.I. Eliseeva, MD, DSc, Associate Professor, Department of Hospital Pediatrics ${ }^{6}$;

S.K. Ignatov, DSc, Professor, Department of Photochemistry and Spectroscopy ${ }^{5}$;

T.V. Li, MD, PhD, Neurologist, Center for Neurology and Rehabilitation;

I.Z. Batyrshin, DSc, Professor, Research Computing Center ${ }^{8}$

${ }^{1}$ Kazan Federal University, 18 Kremlyovskaya St., Kazan, Republic of Tatarstan, 420000, Russian Federation;

${ }^{2}$ City Clinical Hospital No.38, 22 Chernyshevsky St., Nizhny Novgorod, 603005, Russian Federation;

${ }^{3}$ Pulmonology Research Institute, Federal Biomedical Agency of the Russian Federation, 32, 11th Parkovaya St.,

Moscow, 105077, Russian Federation;

${ }^{4}$ I.M. Sechenov First Moscow State Medical University, 8/2 Trubetskaya St., Moscow, 119991, Russian Federation;

${ }^{5}$ Lobachevsky State University of Nizhni Novgorod, 23 Prospekt Gagarina, Nizhny Novgorod, 603950,

Russian Federation;

${ }^{6}$ Nizhny Novgorod State Medical Academy, 10/1 Minin and Pozharsky Square, Nizhny Novgorod, 603005,

Russian Federation;

${ }^{7}$ Central Clinical Hospital of the Russian Academy of Sciences, 1a Litovsky blvd, Moscow, 117593,

Russian Federation;

${ }^{8}$ Instituto Politécnico Nacional (CIC-IPN), Av. Juan de Dios Bátiz, Esq. Miguel Othón de Mendizábal S/N,

Gustavo A. Madero, 07738, D.F., México

The aim of the investigation was to assess the significance of the content of metabolites of the nitric oxide, sICAM- 1 and sICAM- 3 in blood serum and in exhaled breath condensate, the serum level of endothelin-1 as systemic and topical markers of inflammation in patients with COPD, and their correlations with the parameters of lung ventilation function.

Materials and Methods. 91 patients with COPD, aged from 46 to 67, and 21 healthy, non-smoking volunteers took part in the study. The material for investigation was blood serum and exhaled breath condensate.

Results. The severity of progression of COPD was linked with an increase in the serum content of sCD50, sCD54, ET-1, as well as in the concentrations of metabolites of nitric oxide in blood and in exhaled breath condensate. For the patients with COPD we determined the associations between the function of pulmonary ventilation and the levels of ET-1, sICAM-1, sICAM- 3 and the value of $\Sigma N_{2}^{-} / N_{3}^{-}$. The resulting correlations between the concentration of soluble adhesion molecules, the values of nitrosative stress, and ET-1 level indicate that they are involved in the genesis of chronic inflammation in COPD patients.

Key words: chronic obstructive pulmonary disease; COPD; endothelin-1; ET-1; nitrosative stress; soluble molecules of adhesion ICAM1 and ICAM-3; exhaled breath condensate.

The steady increase in the prevalence of chronic obstructive pulmonary disease (COPD) and the mortality rate associated with this pathology indicate the importance of studying the pathogenic mechanisms of development of this disease [1]. The identification of new activity markers and the progression of inflammation are key tasks in the studies of these mechanisms.

The result of the immune-mediated mechanisms of inflammation in response to damaging factors is the excessive migration of effector cells to the

For contacts: Nailya I. Kubysheva, e-mail: aibolit70@mail.ru 
lesion site. Cellular adhesion molecules, ICAM-1 and ICAM-3, stimulate the migration of these cells (neutrophils, monocytes, T-lymphocytes) through the alveolar-capillary membranes to the inflammation site. These molecules can be simultaneously present in membrane-bound form on the surface of the cells, and in soluble form in various biological fluids [2, 3]. Soluble differentiating adhesion molecules are formed by the proteolytic shedding of membrane proteins and/ or alternative splicing of matrix RNA [2]. One of the main mechanisms of the immunomodulatory action of the soluble forms of the membrane molecules is ligandbinding and the prevention of the interaction with the membrane form of the antigen and also its transsignal function [3-5]. Imbalance of the content of the soluble factors under study can lead to modulation of the intercellular membrane interactions and to changes in immunological reactivity in many diseases. At present the role of the soluble forms of molecules of cellular adhesion ICAM-1 (sICAM-1, sCD54) and ICAM-3 (sICAM-3, sCD50) in the progression of systemic and topical inflammation in COPD pathogenesis is unclear. However, the current widespread use of non-invasive methods of diagnosis points at the value of studying sICAM-1 and sICAM-3 levels in the exhaled breath condensate (EBC) of patients with COPD during periods of stability and exacerbation.

Soluble forms of ICAM- 1 and ICAM- 3 can modulate the adhesion of leucocytes to the endothelium of vessels and thus change the functional activity and the morphological structure of the endothelial cells [4-7]. Damage to the endothelium and the development of endothelial dysfunction account for the formation of the most significant systemic manifestations (comorbid states) of COPD and mainly result from the excessive secretion of endothelin-1 (ET-1) by the cells of the vascular endothelium [8]. ET-1 belongs to a class of regulatory peptides and plays a key role in processes involved in fibrogenesis of vascular walls and bronchi, in the induction and maintenance of vasoconstriction and bronchoconstriction, as well as in the steady progression of chronic inflammation [9]. ET-1 level is increased in the blood serum in diseases caused by smoking, endothelial dysfunction and pulmonary hypertension [10-12]. It has been determined that the ET-1 concentration in blood, sputum, and EBC in patients with COPD is associated with the partial pressure of oxygen in the arterial blood [13, 14]. But further studies are required to determine the meaning of changes in ET-1 production in the case of progression of the functional and structural pulmonary impairments, depending on the stage and severity of the COPD.

The development of endothelial dysfunction is pathogenically connected with changes in the secretion of nitric oxide (NO) which has a broad bioregulatory effect [15]. The main source of formation of NO molecules is the inducible form of NO-synthase (iNOS), the concentration of which increases dramatically during intensification of inflammation in many diseases [16].
Active formation of nitric oxide and its metabolites causes damage to the proteins and lipids of cellular membranes, inhibits DNA synthesis, increases the intensity of oxidative and nitrosative stress, and can damage the structure of the vascular endothelium. In inflammation NO can also be synthesized non-enzymatically as a result of the reduction of nitrites and nitrates to nitric oxide $[17,18]$. Our earlier works showed increase of nitric oxide metabolite concentration in EBC as the level of bronchial asthma was reducing [19], as well as increase of systemic and topical levels of $\mathrm{NO}$ derivatives and their interconnection with apoptosis markers both in the respiratory tract and circulation in patients with COPD exacerbation [20]. However, the features of the changes in the indicators of nitrosative stress in different COPD periods (stability and exacerbation) remain little studied.

For a complete understanding of the pathogenic mechanisms of COPD progression there is a need for monitoring the markers of endothelial dysfunction, nitrosative stress and immune response at different stages and phases of the disease and then analyzing their correlation with the indicators of chronic inflammation which we have investigated.

The aim of the investigation was to assess the significance of the content of metabolites of the nitric oxide, sICAM-1 and sICAM-3 in blood serum and in exhaled breath condensate, the serum level of endothelin-1 as systemic and topical markers of inflammation in patients with COPD, and their correlations with the parameters of lung ventilation function.

Materials and Methods. COPD was diagnosed in accordance with the criteria of the Global Initiative for Chronic Obstructive Lung Disease (GOLD) [1]. According to the GOLD definition, COPD exacerbation is an acute event characterized by a worsening of respiratory symptoms that goes beyond normal daily fluctuations and leads to a change in the therapy used.

The study involved 112 people. The reference group included healthy non-smoking volunteers $(n=21)$, while the patients with COPD $(n=91)$ were divided into four groups:

patients with exacerbation of moderate COPD ( $n=21)$ - GOLD II exacerbation;

patients with a stable course of moderate COPD $(n=23)$ - GOLD II stable;

patients with exacerbation of severe COPD $(n=22)-$ GOLD II exacerbation;

patients with a stable course of severe COPD $(n=25)$ - GOLD II stable.

The study was performed in accordance with the Helsinki Declaration accepted in June 1064 (Helsinki, Finland) and reviewed in October 2003 (Edinburgh, Scotland) and approved by the Ethical Committee of the Pulmonology Research Institute of the Federal Biomedical Agency. Every patient gave their informed consent.

We selected the patients according to the following criteria: aged 40 or older, smoking history of around 10 
Table 1

Functional characteristics of patients with COPD and healthy non-smoking volunteers $(X \pm \delta)$

\begin{tabular}{lccc}
\hline & \begin{tabular}{c} 
Healthy \\
\multicolumn{1}{c}{ Parameters }
\end{tabular} & \multicolumn{2}{c}{ COPD } \\
& $\begin{array}{c}\text { non-smoking } \\
\text { volunteers } \\
\text { (control) }\end{array}$ & GOLD II & GOLD III \\
\hline Number & 21 & 44 & 47 \\
\hline Age (years) & $53.1 \pm 7.8$ & $56.1 \pm 4.6$ & $63.2 \pm 4.3$ \\
\hline Smoking index (packs/year) & 0 & $37.5 \pm 5.8$ & $39.2 \pm 4.2$ \\
\hline FEV1 (\%) & $105.7 \pm 3.9$ & $62.8 \pm 4.6$ & $40.5 \pm 3.9$ \\
\hline FEV1/FVC (\%) & $108.1 \pm 3.7$ & $61.6 \pm 4.4$ & $49.1 \pm 7.9$ \\
\hline Inspiratory capacity (\%) & $110.1 \pm 2.52$ & $68.6 \pm 7.9$ & $63.1 \pm 7.5$ \\
\hline
\end{tabular}

packs/year; partially reversible obstruction after taking short-term-effect bronchodilators $\quad(30 \%<$ FEV $1<80 \%$; FEV1/FVC $<70 \%$, where FEV1 is the forced expiratory volume per second; FVC is the forced volume vital capacity; FEV1/FVC is known as the Tiffeneau index); clinical symptoms of COPD exacerbation (intensified cough, dyspnea, change in the character and/or sputum volume).

Exception criteria were as follows: bronchial asthma and other allergic diseases; pneumonia at the point of hospitalization; expressed congestive heart failure; severe arterial hypertension; decompensated diabetes mellitus; conditions requiring long-term intake of systemic glucocorticoids.

The study of the respiratory function was performed on a computer Spirograph, the SpiroLab III (MIR, Italy) by analyzing the "flow-volume" curve and by evaluation of the FEV1 and FEV1/FVC, and the parameters of inspiratory capacity. The relevant characteristics of the COPD patients are presented in Table 1.

Preparation of blood serum and exhaled breath condensate. In the morning blood samples were taken from the medial cubital vein of the fasting patients under examination. The samples were immediately centrifuged at $3,000 \mathrm{rpm}$ for $10 \mathrm{~min}$. The serum samples were extracted and stored at a temperature of $80^{\circ} \mathrm{C}$.

The RTube (Respiratory Research, USA) system, which prevents saliva from getting into the sample, was used to collect EBC within 20 min after mouth rinsing.

The amount of ET-1 in the blood serum was determined using an enzyme-linked immunosorbent assay (ELISA) with a set of reagents from Biomedica Gruppe (Austria) according to the method described by the manufacturer.

Determination of nitric oxide metabolites in blood serum and exhaled breath condensate. The total concentration of $\mathrm{NO}_{2}^{-} / \mathrm{NO}_{3}^{-}\left(\sum \mathrm{NO}_{2}^{-} /\right.$ $\left.\mathrm{NO}_{3}^{-}\right)$in the $\mathrm{EBC}$ and that of nitrites $\left(\mathrm{NO}_{2}^{-}\right)$in the blood serum was determined spectrophotometrically at a wavelength of $540 \mathrm{~nm}$ with a Humalazer 2000 (Human $\mathrm{GmbH}$, Germany) [21], using Griess reagent and a cadmium deoxidizer.

Determination of the amount of soluble molecules of adhesion, sICAM-1 and SICAM-3. The concentration of these molecules in the serum and EBC was measured by means of an ELISA test. To determine their concentration we used goat polyclonal antibodies against human leucocyte antigens and the mouse monoclonal antibodies ICO-60 and ICO-184 against antigens CD54 and CD50 conjugated with horseradish peroxidase [22]. The measurements were performed with a Multiscan MC ELISA reader (Labsystems, Finland) at a wavelength of $405 \mathrm{~nm}$. The results are provided in units per milliliter $(\mathrm{U} / \mathrm{ml})$.

Statistical analysis. The data are provided as the mean and standard deviation $(\mathrm{M} \pm \mathrm{SD})$. For the normality distribution we used the Shapiro-Wilk's test. Further processing of the results was carried out with ANOVA and Student-t tests. To evaluate the correlation we used the Pearson ratio $(r)$. The differences were considered statistically significant at $p<0.05$. The statistical analysis was performed with BIOSTAT and Statgraphics v. 5.

Results. The serum concentration of ET-1 in all the examined patients was statistically significantly higher than in the healthy non-smoking volunteers $(0.67 \pm$ $0.27 \mathrm{fmol} / \mathrm{ml}$; ANOVA, $p=0.006$ ) (Figure 1). We did not find any significant differences in the ET-1 concentration between exacerbation and stable periods of COPD in any of the groups of patients. However, there was a tendency toward a linear increase in the level of the peptide that corresponded to the severity (with growth severity) of COPD. The ET-1 concentration in the GOLD III exacerbation group was 1.4 times higher

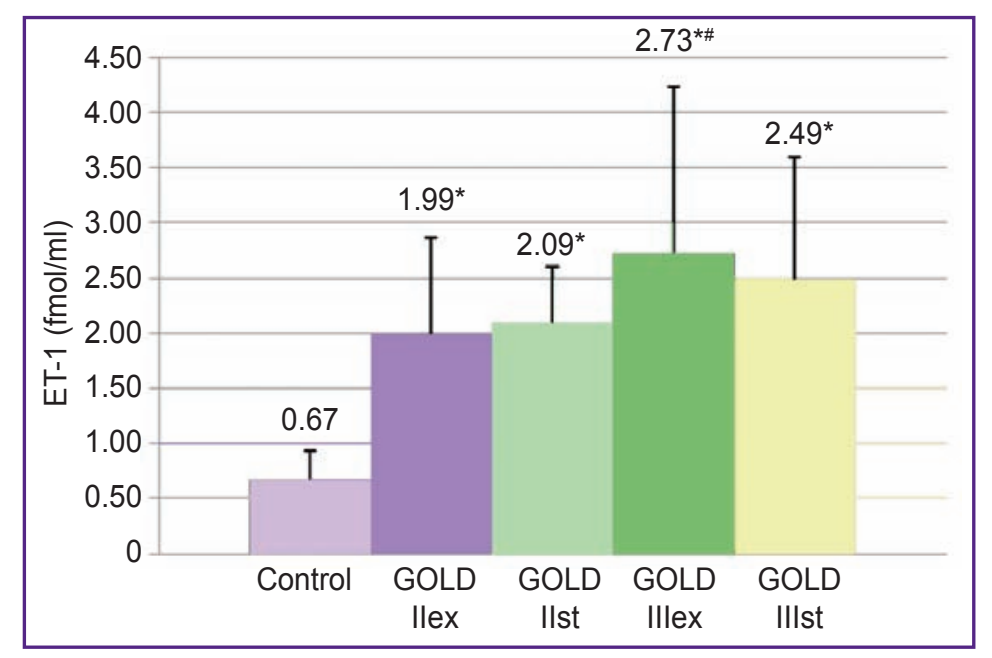

Figure 1. The concentration of endothelin-1 in blood serum in patients with COPD during exacerbation and stable periods

* Statistically significant differences in the values compared to healthy non-smoking volunteers, $p<0.05$; \# to patients with moderate COPD during exacerbation, $p<0.05$. GOLD Ilex - GOLD II exacerbation period; GOLD IIst - GOLD II stable period 
than in the GOLD II exacerbation group $(2.73 \pm 1.51$ and $1.99 \pm 0.81 \mathrm{fmol} / \mathrm{ml}$ respectively, $p=0.04)$. We identified negative associations between the value of inspiratory capacity and the serum concentration of ET-1 $(r=-0.53 ; p=0.02)$ in all the studied patients with COPD (Table 2).

The level of metabolites of nitric oxide in both the blood serum and EBC in patients with COPD was much higher than in the healthy non-smoking volunteers (ANOVA, $p=0.001$ and $p=0.002$, respectively) (Figure 2).

No significant differences were identified in the concentrations of the products of nitric oxide in the blood serum and the EBC between the stable and exacerbation periods in patients from groups GOLD II and GOLD III. We registered a progressive increase in the amount of $\mathrm{NO}_{2}^{-}$in the blood circulation and of $\Sigma \mathrm{NO}_{2}^{-} / \mathrm{NO}_{3}^{-}$in the $\mathrm{EBC}$ in patients with COPD along with increasing of degree of the airway obstruction. The serum concentration of $\mathrm{NO}_{2}^{-}$ in patients with severe COPD $(7.4 \pm 3.7 \mu \mathrm{mol} / \mathrm{ml})$ and during stable periods $(8.2 \pm 4.46 \mu \mathrm{mol} / \mathrm{ml})$ was 1.8 times higher than in patients from the GOLD II group in the same periods of the disease $(p=0.001$ and $p=0.002$, respectively).

The total concentration of $\Sigma \mathrm{NO}_{2}^{-} / \mathrm{NO}_{3}^{-}$in the $\mathrm{EBC}$ of all patients from the GOLD III groups $(11.4 \pm 5.7 \mu \mathrm{mol} / \mathrm{ml}$ during exacerbation and $12.4 \pm 5.8 \mu \mathrm{mol} / \mathrm{ml}$ during stable

Table 2

Correlation between the concentrations of ET-1, NO- , sICAM-1, sICAM-3 and the $\mathrm{\Sigma NO}_{2}^{-} / \mathrm{NO}_{3}^{-}$in different biological fluids in relation to parameters of lung function in patients with COPD

\begin{tabular}{lccc}
\hline \multicolumn{1}{c}{ Parameters investigated } & FEV1 $(\%)$ & FEV1/FVC (\%) & Inspiratory capacity (\%) \\
\hline Endothelin-1 (serum) & $r=-0.25 ; p=0.24$ & $r=-0.29 ; p=0.21$ & $r=-0.53 ; p=0.02$ \\
\hline$\sum \mathrm{NO}_{2}^{-} \mathrm{NO}_{3}^{-}(\mathrm{EBC})$ & $r=-0.31 ; p=0.09$ & $r=-0.17 ; p=0.32$ & $r=-0.65 ; p=0.01$ \\
$\mathrm{NO}_{2}^{-}$(serum) & $r=-0.28 ; p=0.26$ & $r=-0.28 ; p=0.24$ & $r=-0.21 ; p=0.35$ \\
sICAM-1 (serum) & $r=-0.43 ; p=0.03$ & $r=-0.3 ; p=0.1$ & $r=-0.48 ; p=0.35$ (GOLD III) \\
sICAM-1 (EBC) & $r=-0.26 ; p=0.28$ & $r=0.51 ; p=0.01$ & $r=0.15 ; p=0.4$ \\
sICAM-3 (serum) & $r=0.27 ; p=0.26$ & $r=-0.31 ; p=-0.09$ & $r=-0.56 ; p=0.02$ (GOLD III) \\
sICAM-3 (EBC) & $r=0.1 ; p=0.65$ & $r=-0.25 ; p=-0.32$ & $r=-0.28 ; p=0.31$ \\
\hline
\end{tabular}

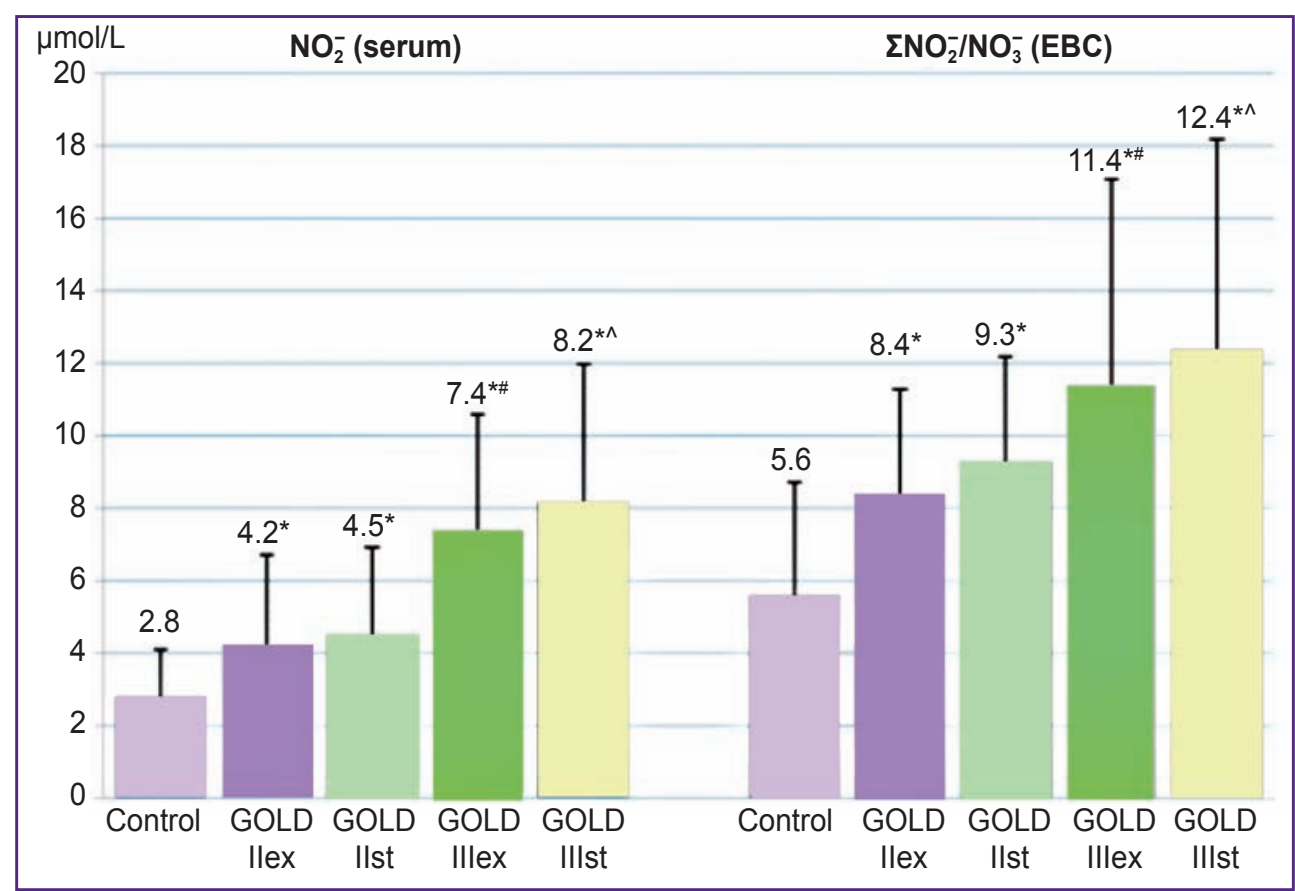

Figure 2. The level of nitrites $\left(\mathrm{NO}_{2}^{-}\right)$in blood serum and total concentration of $\Sigma \mathrm{NO}_{2}^{-} / \mathrm{NO}_{3}^{-}$ in the exhaled breath condensate in COPD patients during exacerbation and stable periods

* Statistically significant differences in the values compared to healthy non-smoking volunteers, $\mathrm{p}<0.05$; \# to patients with moderate COPD during exacerbation; $p<0.05$; ${ }^{\wedge}$ to patients with moderate COPD during stable period, $p<0.05$. GOLD Ilex - GOLD II exacerbation period; GOLD IIst — GOLD II stable period 
Table 3

Correlation between the concentrations of ET-1, $\mathrm{NO}_{2}^{-}$and the levels of sICAM-1, sICAM-3 in different biological fluids in patients with COPD

\begin{tabular}{lccccc}
\hline Parameters investigated & $\begin{array}{c}\text { Endothelin-1 } \\
\text { (serum) }\end{array}$ & $\begin{array}{c}\text { sICAM-1 } \\
\text { (serum) }\end{array}$ & $\begin{array}{c}\text { sICAM-1 } \\
\text { (EBC) }\end{array}$ & $\begin{array}{c}\text { sICAM-3 } \\
\text { (serum) }\end{array}$ & $\begin{array}{c}\text { sICAM-3 } \\
\text { (EBC) }\end{array}$ \\
\hline Endothelin-1 (serum) & - & $r=0.73 ; p=0.01$ & $r=0.17 ; p=0.34$ & $r=0.45 ; p=0.03$ & $r=0.25 ; p=0.28$ \\
$\mathrm{NO}_{2}^{-}$(serum) & $r=0.39 ; p=0.01$ & $r=0.3 ; p=0.21$ & $r=0.31 ; p=0.28$ & $r=0.24 p=0.25$ & $r=0.47 ; p=0.03$ \\
\hline
\end{tabular}

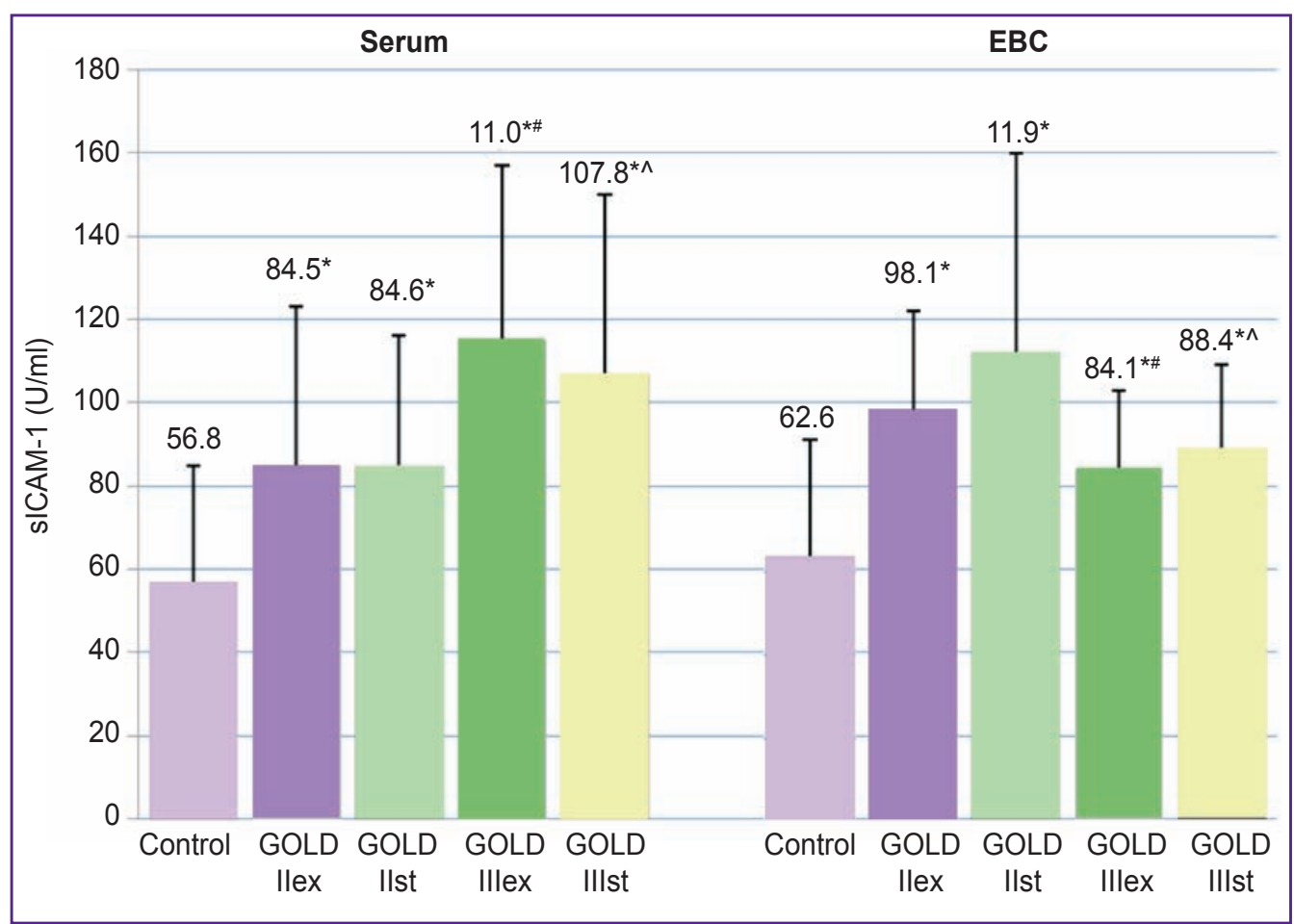

Figure 3. Concentration of sICAM-1 molecules in blood serum and exhaled breath condensate in COPD patients during exacerbation and stable periods

* Statistically significant differences in the values compared to healthy non-smoking volunteers, $p<0.05$; " to patients with moderate COPD during exacerbation; $p<0.05$; ${ }^{\wedge}$ to patients with moderate COPD during stable period, $p<0.05$. GOLD Ilex - GOLD II exacerbation period; GOLD IIst GOLD II stable period

periods) was 1.3 times higher than the level of the studied molecules in the GOLD II groups $(p=0.028$ and $p=0.026$, respectively) (See Figure 2 ). We identified a negative correlation between the endobronchial concentration of $\Sigma \mathrm{NO}_{2}^{-} / \mathrm{NO}_{3}^{-}$and the inspiratory capacity IC\% (where IC\% represents the proportion of the normal values) $(r=-0.65 ; p=0.01)$ in the examined patients with COPD (See Table 2).

All the examined patients with COPD had a positive correlation $(r=0.39 ; p=0.04)$ between their serum concentrations of ET-1 and $\mathrm{NO}_{2}^{-}$(Table 3). Furthermore, the patients with moderate COPD had a high correlation between the molecular markers under study $(r=0.72$; $\mathrm{p}=0.001$ ).

The concentrations of sICAM-1 in the blood serum and $E B C$ in the COPD patients was statistically significantly higher than in the reference group (ANOVA, $p=0.006$ and $p=0.001$, respectively) (Figure 3 ).

The concentration of SICAM-3 in the EBC was increased in all the patients with COPD compared to the healthy non-smoking volunteers $(220.2 \pm 81.1 \mathrm{U} / \mathrm{ml}$; ANOVA, $p=0.05$ ) and did not differ statistically between the GOLD II and GOLD III groups of patients (Figure 4). However, the serum level of sICAM-3 was only higher than the values for the reference group $(351.4 \pm 45.7 \mathrm{U} / \mathrm{ml})$ in the case of severe COPD $(p<0.05)$.

It was identified that the increase in the concentrations of SICAM-1 and SICAM-3 was connected with increased COPD severity. Their values in blood serum in the patients from the GOLD III groups was statistically significantly higher than in the GOLD II exacerbation and GOLD II stable groups $(p<0.05)$. 


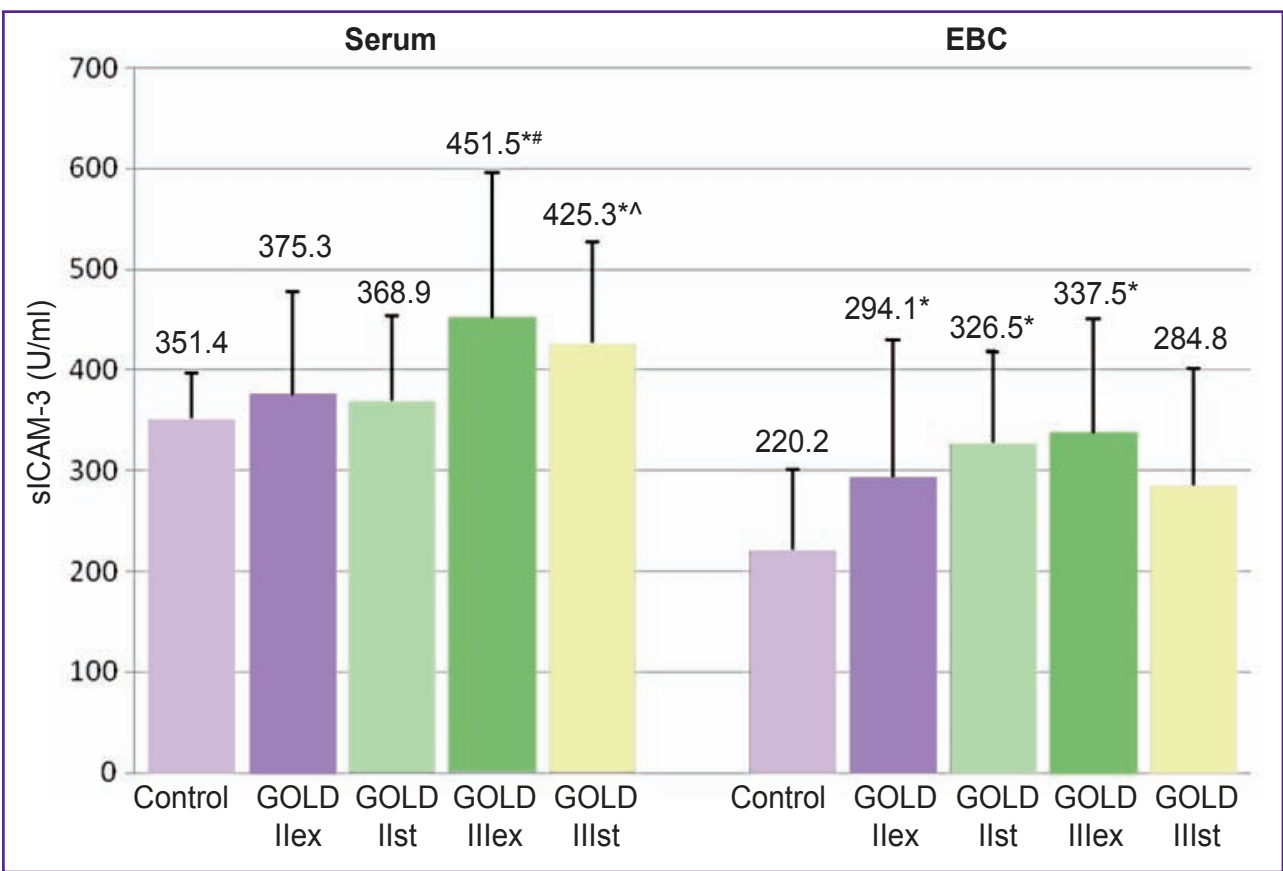

Figure 4. Concentration of SICAM-3 molecules in blood serum and in exhaled breath condensate in COPD patients during exacerbation and stable periods

* Statistically significant differences in the values compared to healthy non-smoking volunteers, $p<0.05$; \# to patients with moderate COPD during exacerbation; $p<0.05$; $\wedge$ to patients with moderate COPD during stable period, $p<0.05$. GOLD Ilex - GOLD II exacerbation period; GOLD Ilst — GOLD II stable period

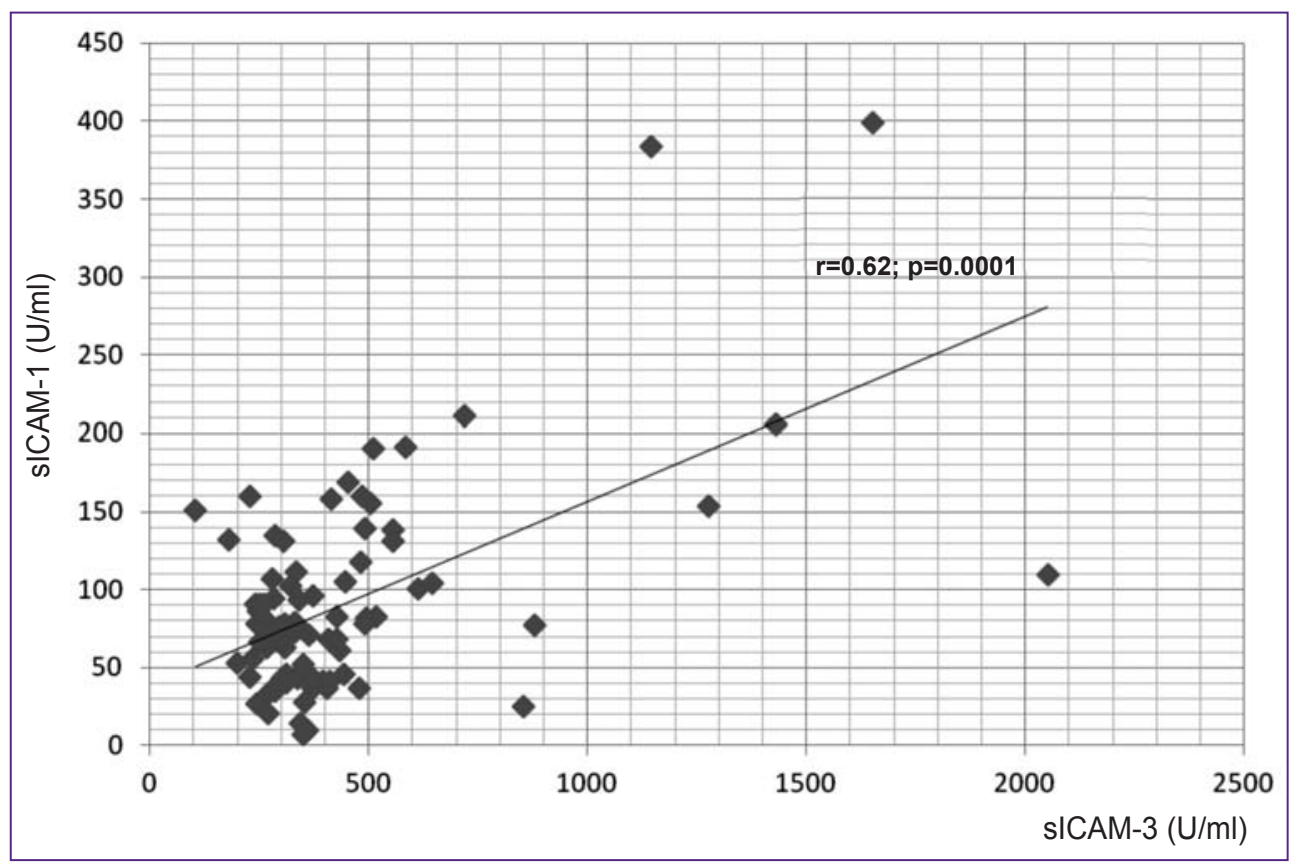

Figure 5. Correlation between the levels of sICAM-1 and sICAM-3 in blood serum in patients with COPD

In the EBC, the SCD54 levels in severe COPD were statistically significantly lower than the values in the group of patients with moderate bronchoobstructive impairments $(p<0.05)$.
No major differences in the amounts of SCD50 and sCD54 were detected in the biological fluids representing the exacerbation and stable periods in the two groups of patients with COPD. 


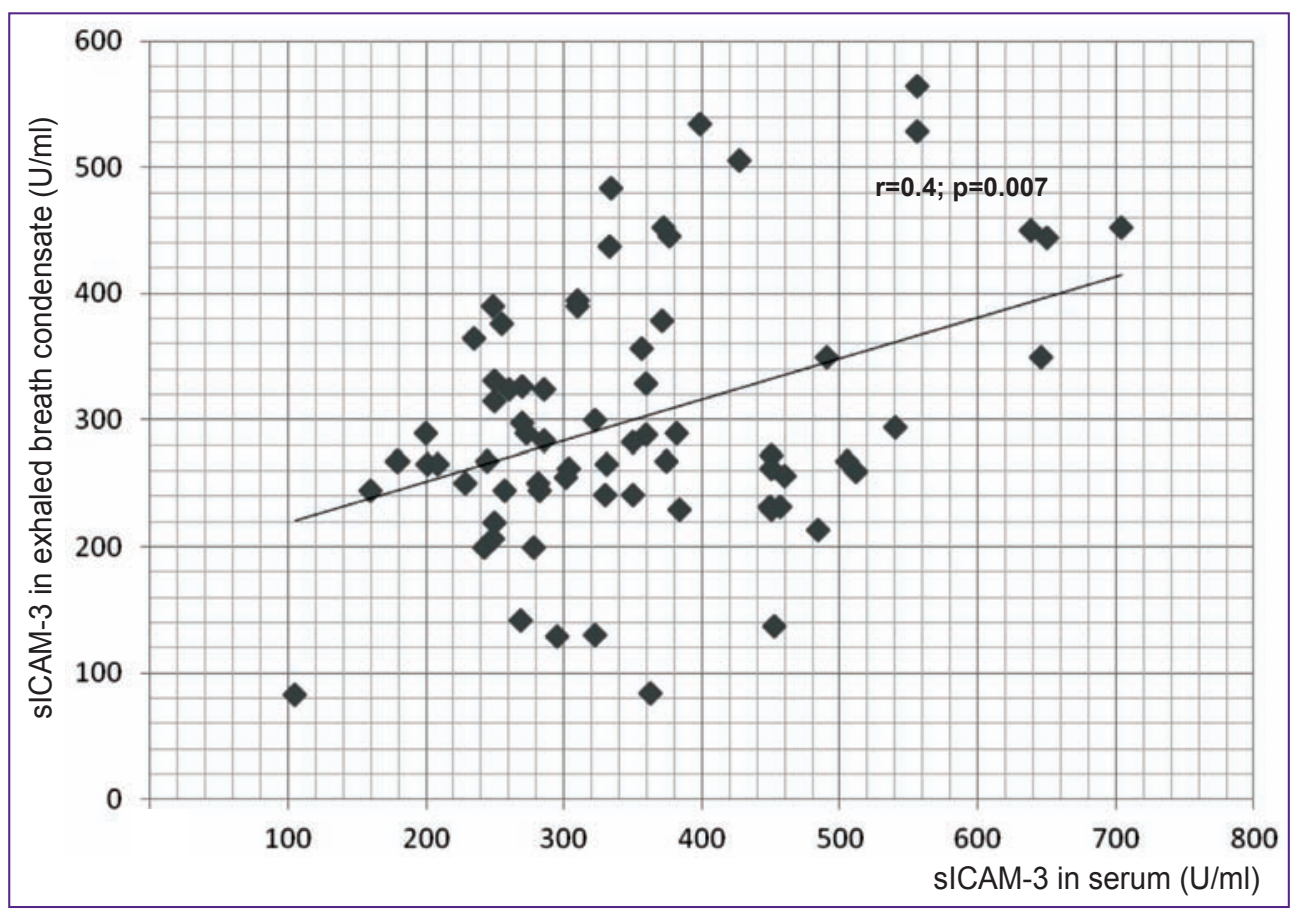

Figure 6. Correlation between the serum level of SICAM-3 and the concentration of SICAM-3 in exhaled breath condensate in COPD patients

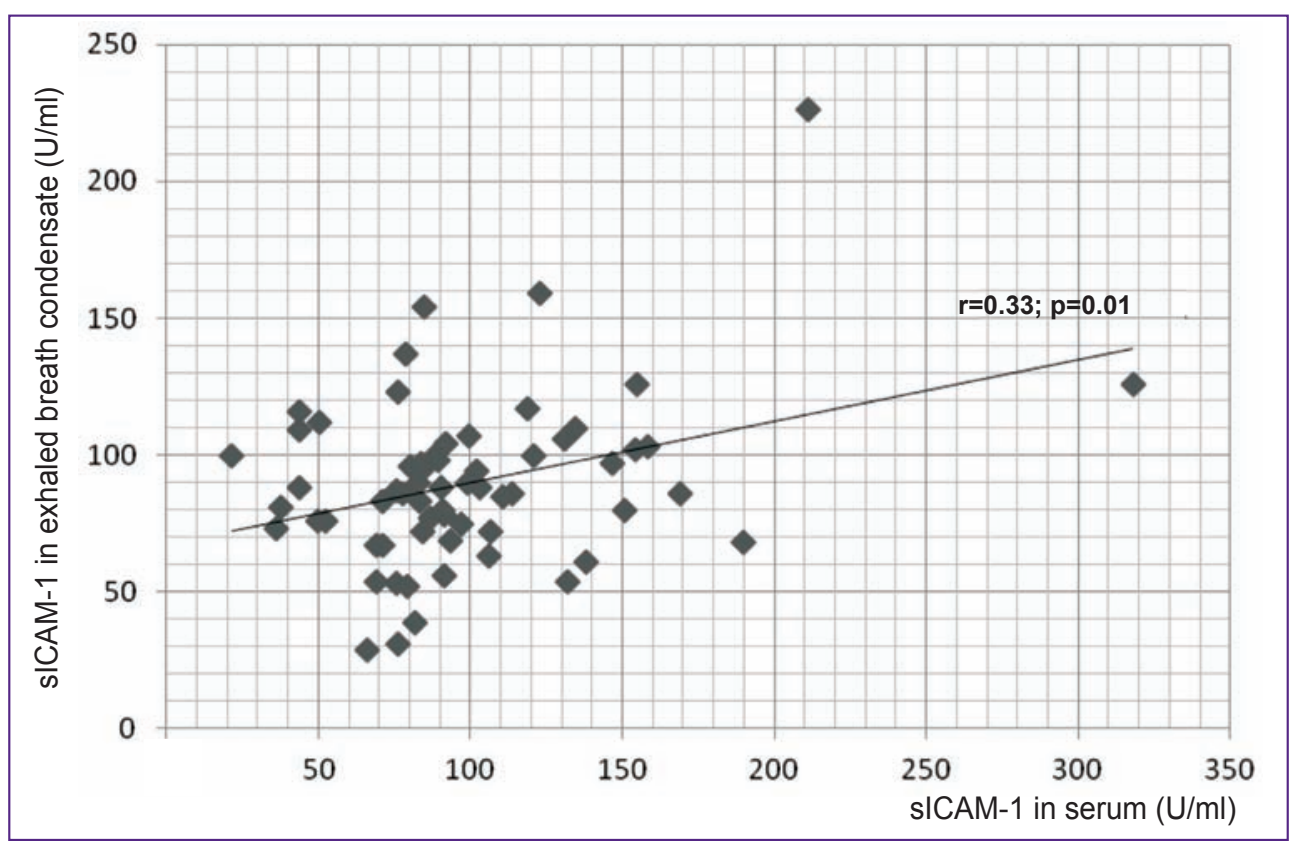

Figure 7. Correlation between the serum level of sICAM-1 and the concentration of SICAM-1 in the exhaled breath condensate in COPD patients

Analysis of the associations between the concentrations of the soluble molecules SICAM-1 and sICAM-3, as well as the parameters of nitrosative stress, endothelial dysfunction and the parameters of lung function revealed the following correlations:

a positive correlation between the serum concentrations of SICAM- 1 and SICAM-3 $(r=0.62$; $\mathrm{p}=0.0001$ ) (Figure 5); a positive correlation between the serum level of sICAM-3 and the concentration of SICAM-3 in EBC $(r=0.4 ; p=0.007)$ (Figure 6);

a positive correlation between the serum level of sICAM-1 and the concentration of SICAM-1 in EBC $(r=0.33 ; p=0.01)$ (Figure 7);

a negative correlation between the serum levels of sICAM-1 and FEV1 $(r=-0.43 ; p=0.03$ ) (See Table 2); 
a positive correlation between the level of sICAM- 3 in EBC and the value of FEV1/FVC $(r=0.51 ; p=0.01)$ (See Table 2);

a negative correlation between the inspiratory capacity and the concentrations of sICAM-1 ( $p=-0.48$; $p=0.03)$ and sICAM-3 $(r=-0.56 ; p=0.02)$ in patients with severe COPD (See Table 2);

a positive correlation between ET-1 and the concentrations of sICAM-1 $(r=0.73 ; p=0.01)$ and sICAM-3 ( $r=0.45 ; p=0.03$ ) (See Table 3);

a positive correlation between the level of SICAM-3 in $\mathrm{EBC}$ and the concentration of $\mathrm{NO}_{2}^{-}(r=0.47 ; p=0.03)$ (See Table 3).

Discussion. The results of this study showed excessive serum and endobronchial accumulation of soluble molecules of adhesion ICAM-1 in all the COPD patients compared with the reference group. The concentration of circulating sICAM-3 increased only in cases of severe COPD. However, at a topical level, there was an increase in the amount of these proteins in all the groups of patients with COPD compared to the healthy non-smoking volunteers. It is worth mentioning that the growth in the concentration of these soluble proteins in the blood circulation was associated with the lowered bronchial patency found in COPD. The registered linear correlation of the amount of SICAM-1 and the level of SICAM-3 in the blood serum confirms the unidirectionality of the changes in the tested markers of inflammation as COPD progresses.

During the exacerbation and stable periods of the disease the concentration of these soluble proteins in the biological fluids investigated for each group did not differ significantly. Thus, changes in the concentrations of SICAM-1 and SICAM-3 do not depend on the stage of COPD.

The functional significance of SICAM-1 and SICAM-3 is determined by their participation in the modulation of the immune response $[4,5]$. In particular, they can inhibit activation, adhesion and cell migration. Soluble molecules of CD54 can compete with the membrane form of ICAM-1 for binding with the antigens LFA-1 and Mac-1 on lymphocytes and monocytes, and thus, lower the adhesion of these leucocytes to the endothelium [2, $4,5]$. sCD50 molecules, interacting with homological receptors on the surfaces of antigen-presenting cells can inhibit initiation of the immune response processes [2]. So the excessive production of circulating molecules of sICAM-1 and sICAM-3 in patients with COPD may be part of a restrictive mechanism helping to inhibit excessive migration of inflammatory cells to phologogenic areas, but therefore leading to impairment of an adequate immune response. In this case the increase in the concentration these soluble molecules, in combination with the progression of airway obstruction, can be an unfavorable prognostic factor in COPD, because the capacity of the effector cells to carry out their function at the lesion site can be inhibited. But, still, it is possible that the increased concentrations of the soluble molecules CD54 and CD50 in circulation can have an anti-inflammatory effect and stimulate the self-limiting mechanisms of the inflammatory response. Previously, Schmal et al. [23] have suggested that, in the lungs, sICAM-1 can function either as a pro-inflammatory or an anti-inflammatory mediator depending on the anatomical localization of the release of this protein. It was shown that the shedding of ICAM-1 molecules from the surface of macrophages and epithelial cells in the distal sections of the respiratory tract leads to increased damage to the lung tissue due to activation of the alveolar macrophages and their stimulation into excessive production of cytokines - MIP-2 and TNF- $\alpha$. Taking into account that the distal parts of the respiratory tract are the first to be exposed to damage in COPD patients, high concentrations of the s-forms of the CD54 proteins can play a significant role in the progression of an inflammatory response of the airways.

Thus, increased concentrations of circulating soluble molecules of adhesion at a systemic level can inhibit the development of inflammatory processes while a local increase in these proteins can, by contrast, increase the inflammation in the respiratory tract.

The correlation analysis showed a positive association between the serum and topical concentrations of the soluble molecules of adhesion under study, which can testify to the identity of the mechanisms regulating the production of these molecules in response to the development of systemic and local inflammatory reactions in COPD.

High concentrations of sCD50 and sCD54 can be caused by the intensive release of these proteins from the surface of antigen-positive cells. It is known that activated endobronchial epithelial cells, endothelial cells, fibroblasts and alveolar macrophages are potential sources of the soluble molecules of sICAM-1 and sICAM-3 [23-27]. Hypoxic factors can also have an impact on the increased formation of such adhesion molecules. Chronic hypoxia in patients with severe and very severe COPD have a negative impact on a number of pathogenic links. Madjdpour et al. [28] showed that, in long-term hypoxia, excessive production of TNF- $\alpha$ and a hypoxic inducible factor $\alpha$ (HIF- $\alpha$ ) is activated by alveolar macrophages and as a result the release of soluble molecules of ICAM-1 is stimulated. However, it is known that SCD54 molecules take part in the initiation of secretion of such inflammatory mediators as IL-8, IL-6, TNF- $\alpha, y-I N F$ by endothelial cells and leucocytes $[23,29]$. The above factors, together, can lead to a vicious circle and maintain progression of the systemic inflammatory process, to destructive processes in the respiratory tract and to impairments in pulmonary ventilation in COPD patients.

To clarify the role of the soluble molecules of adhesion in the genesis of COPD-related impairments of pulmonary ventilation we performed a correlation analysis between the amounts of sCD50 and sCD54 and the parameters of lung function. It was noted that 
a decrease in FEV1 values in COPD patients was associated with an increase in the concentration of sICAM-1. Since the level of FEV1 reflects the degree of bronchial obstruction the level of sICAM-1 in blood can, potentially, be regarded as a marker for the progression of bronchial conductivity impairment.

Despite the increase in the concentration of soluble molecules in the EBC in all COPD patients, the level of sCD54 in cases of severe of the disease was statistically much lower in the GOLD II group. The decrease in the topical concentration of ICAM-1 may result from the inactivation of the cells producing it due to the suppression of the immune response in conditions of the induction of fibrogenesis and remodeling of the lung tissue during the treatment of severe COPD. Moreover, the drop in the level of sICAM-1 in the EBC in the GOLD III groups may be caused by augmentation of the programmed of the cells death, producing these soluble adhesion molecules in the respiratory tract. This hypothesis is supported by the results of our previous study where an increase in apoptosis markers in the respiratory tracts of patients with severe COPD was demonstrated [20].

The identified association between the levels of sICAM-1 in the EBC and the FEV1/FVC confirms the pattern of a fall in the topical amount of this inflammation marker as the disease progresses. Moreover, the determined correlations allow considering the amount of sICAM-1 in the EBC to represent a non-invasive marker of COPD progression.

Thus, analysis of our results enables us to refer to the changes in the concentrations of the adhesion molecules ICAM-1 and ICAM-3, present in soluble forms in the blood and EBC as representing the most important pathogenic mechanisms of systemic and topical inflammation in COPD.

Among a wide range of phlogogenic molecules affecting the development of systemic inflammation in COPD one should also mention the vasoactive mediator ET-1 [30]. The results of this study showed an increase in the level of this peptide in all COPD patients compared to the reference group. Maximum accumulation of ET-1 was registered in patients with exacerbation of severe COPD. Thus, activation of an inflammatory process in patients with explicit bronchial obstructive impairments is characterized by a high release of ET-1 into the blood by endothelial cells. The functional ability of ET-1 is its pleiotropy. It is known that excessive accumulation of this vasoactive peptide in response to the realization of an endothelial dysfunction causes initiation of fibrogenesis in the lungs, induction of vaso- and bronchoconstriction [9, 13, 31, 32]. It is probable that the increased concentration of ET-1 in the blood is one of the most unfavorable factors influencing the processes of the remodeling of bronchopulmonary tissue in conditions of the activation and progression of chronic inflammation in COPD.

ET-1 additionally affects the migration of inflammatory cells while also changing their activity and adhesive properties [32, 33]. The identified positive association of ET-1 level and the amount of SICAM-1 and SICAM-3 in blood serum may indicate the general mechanism of participation of these biomarkers in the modulation of immunological reactions and cell migration.

The linear dependency between the increase in the level of nitric oxide metabolites in blood and in the EBC and the progression of COPD severity helps demonstrate the pathogenetic role of nitrosative stress in the development of systemic and topical inflammation in this disease. The increased synthesis of nitric oxide may be caused by activation of inducible NO-synthase which is expressed in macrophages, neutrophils, mast cells, endothelial, epithelial cells and smooth muscle cells $[16,34]$. The increased formation of NO-metabolites in the respiratory tract in COPD can result from the effects of such factors as pathogenic bacteria and viruses, the inhalation of a range of exogenous compounds including cigarette smoke, nitrogen dioxide and fine particles [35-37]. Furthermore, it has been shown [38, 39] that the increase in the amount of nitric oxide products is associated with increased hypoxia in patients with severe COPD. All the above factors can contribute to the accumulation of $\mathrm{NO}$ and its derivatives both in the respiratory tract and in the whole body.

The current study has determined that rising amounts of nitrite $\left(\mathrm{NO}_{2}^{-}\right)$in the blood serum are associated with increases in ET-1 in all the patients with COPD. It is known that ET-1 and NO can both be synthesized by the same cells - epitheliocytes, alveolar macrophages, neutrophils and fibroblasts [9, 15]. Activation of these cells during chronic inflammation contributes to the simultaneous release of different vasoactive mediators and thus the joint participation of ET-1 and NO in the progression of the systemic inflammatory process in COPD cannot be excluded.

We identified positive correlations between the serum concentration of nitrites and the topical level of SICAM-3. ICAM-3 molecules play a particular role in the initiation of the primary contact between T-lymphocytes and antigen-presenting cells in the process of an immune response [40]. sCD50 molecules, by contrast, take part in the suppression of immune reactions by binding with receptor molecules on the surfaces of antigenpresenting cells [40]. Thus, ICAM-3 molecules at high concentrations can cause a blocking effect on the processes of forming immune synapsis and antigen presentation impairing thereby an adequate immune response. The observed correlation between the topical content of SICAM-3 and serum level of nitrites may be the evidence of the possibility of antigen presentation impairment under the influence of nitrosative stress in the airways of COPD patients, which may be one of the causes of disease exacerbation and/or inflammation progression.

The pathogenetic significance of the mediators of inflammation under study in the mechanisms of COPD 
development is confirmed by the negative associations between the serum levels of ET-1, sICAM-1, sICAM-3, the topical concentration of $\Sigma \mathrm{NO}_{2}^{-} / \mathrm{NO}_{3}^{-}$and such parameters of lung function as inspiratory capacity. It is known that a decrease in inspiratory capacity is associated with such pathophysiological impairment as the development of pulmonary hyperinflation, which is manifested by an increase in hypoxia and impairments in respiratory metabolism. The identified associations can testify to a systemic effect of ET-1 and circulating molecules of adhesion ICAM- 1 and SICAM-3 on the structural and functional changes in the respiratory system with the increasing severity of CODP. At the same time the activation of nitrosative stress in the respiratory tract is associated with the progression of hyperinflation and the development of hypoxia in conditions of severe inflammation in this pathology.

Conclusion. Our findings indicate that endothelin-1, metabolites of nitric oxide, sICAM- 1 and SICAM-3 play an important role in the pathogenesis of bronchial obstruction and the steady progression of topical and systemic chronic inflammation in COPD.

The determined associations of lung function parameters and the complex of the examined inflammation markers in COPD patients support the relevance of determining the serum and topical content of sICAM-1, sICAM-3, endothelin-1 level in circulation, and total $\mathrm{NO}_{2}^{-} / \mathrm{NO}_{3}^{-}$concentration as additional systemic and topical indicators of the disease severity degree.

The identified correlations between the concentrations of the soluble molecules of adhesion CD50 and CD54, endothelin-1 and the markers of nitrosative stress provide an opportunity to obtain a more complete picture of the pathogenetic mechanisms of the progression of chronic inflammation both in the respiratory tract and at a systemic level in COPD patients.

Funding of the study. The study was partially supported by projects 156150 and 240844 CONACYT, México and №20.223.2014/K and 15-01-06456 of the Russian Foundation for Basic Research. This work was funded by the subsidy of Russian Government Program of Competitive Growth of Kazan Federal University.

Conflicts of interest. The authors declare no conflict of interests.

\section{References}

1. Global Initiative for Chronic Obstructive Lung Disease (GOLD). Global strategy for diagnosis, management and prevention of chronic obstructive pulmonary disease. NHLBI/ WHO workshop report. Last updated 2013.

2. Novikov V.V., Evsegneeva I.V., Karaulov A.V., Baryshnikov A.Yu. Soluble forms of membrane antigens of immune system cells in social infections. Rossiyskiy bioterapevticheskiy zhurnal 2005; 4(2): 100-105.

3. Rothlein R., Mainolfi E.A., Czajkowski M., Marlin S.D. A form of circulating ICAM-1 in human serum. $J$ Immunol 147(11): 3788-3793.

4. Bleijs D.A., Geijtenbeek T.B., Figdor C.G., van Kooyk Y.
DC-SIGN and LFA-1: a battle for ligand. Trends Immunol 2001; 22(8): 457-463.

5. Kusterer K., Bojunga J., Enghofer M., Heidenthal E., Usadel K.H., Kolb H., Martin S. Soluble ICAM-1 reduces leukocyte adhesion to vascular endothelium in ischemiareperfusion injury in mice. Am J Physiol 1998; 275(2 Pt 1): G377-G380.

6. Ridker P.M., Hennekens C.H., Roitman-Johnson B., Stampfer M.J., Allen J. Plasma concentration of soluble intercellular adhesion molecule 1 and risks of future myocardial infarction in apparently healthy men. Lancet 1998; 351(9096): 88-92, https://doi.org/10.1016/s0140-6736(97)09032-6.

7. Constans J., Conri C. Circulating markers of endothelial function in cardiovascular disease. Clinica Chimica Acta 2006; 368(1-2): 33-47, https://doi.org/10.1016/j. cca.2005.12.030.

8. Kwon Y.S., Chi S.Y., Shin H.J., Kim E.Y., Yoon B.K., Ban H.J., Oh I.J., Kim K.S., Kim Y.C., Lim S.C. Plasma C-reactive protein and endothelin-1 level in patients with chronic obstructive pulmonary disease and pulmonary hypertension. J Korean Med Sci 2010; 25(10): 1487-1491, https://doi.org/10.3346/jkms.2010.25.10.1487.

9. Wort S.J., Woods M., Warner T.D., Evans T.W. Mitchell J.A. Endogenously released endothelin-1 from human pulmonary artery smooth muscle promotes cellular proliferation. Am J Respir Cell Mol Biol 2001; 25(1): 104-110, https://doi.org/10.1165/ajrcmb.25.1.4331.

10. Santos S., Peinado V.I., Ramírez J., Melgosa T., Roca J., Rodriguez-Roisin R., Barberà J.A. Characterization of pulmonary vascular remodelling in smokers and patients with mild COPD. Eur Respir J 2002; 19(4): 632-638, https://doi.org/ 10.1183/09031936.02.00245902.

11. Wright J.L., Tai H., Churg A. Cigarette smoke induces persisting increases of vasoactive mediators in pulmonary arteries. Am J Respir Cell Mol Biol 2004; 31(5): 501-509, https://doi.org/10.1165/rcmb.2004-0051oc.

12. Dominguez-Avila N., Ruiz-Castañeda G., GonzálezRamírez J., Fernandez-Jaramillo N., Escoto J., SánchezMuñoz F., Marquez-Velasco R., Bojalil R., EspinosaCervantes R., Sánchez F. Over, and underexpression of endothelin 1 and TGF-beta family ligands and receptors in lung tissue of broilers with pulmonary hypertension. Biomed Res Int 2013; 2013: 190382, https://doi.org/10. 1155/2013/190382.

13. Carratu P., Scoditti C., Maniscalco M., Seccia T.M., Di Gioia G., Gadaleta F., Cardone R.A., Dragonieri S., Pierucci P., Spanevello A., Resta O. Exhaled and arterial levels of endothelin-1 are increased and correlate with pulmonary systolic pressure in COPD with pulmonary hypertension. BMC Pulm Med 2008; 8(1): 20, https://doi.org/10.1186/1471-24668-20.

14. Roland M. Sputum and plasma endothelin-1 levels in exacerbations of chronic obstructive pulmonary disease. Thorax 2001; 56(1): 30-35, https://doi.org/10.1136/ thorax.56.1.30.

15. Bourque S.L., Davidge S.T., Adams M.A. The interaction between endothelin-1 and nitric oxide in the vasculature: new perspectives. Am J Physiol Regul Integr Comp Physiol 2011; 300(6): R1288-R1295, https://doi.org/10.1152/ ajpregu.00397.2010.

16. Nussler A.K., Billiar T.R. Inflammation, immunoregulation, and inducible nitric oxide synthase. J Leukoc Biol 1993; 54(2): 171-178. 
17. Zweier J.L., Samouilov A., Kuppusamy P. Nonenzymatic nitric oxide synthesis in biological systems. Biochim Biophys Acta 1999; 1411(2-3): 250-262, https://doi. org/10.1016/s0005-2728(99)00018-3.

18. Dejam A., Hunter C.J., Schechter A.N., Gladwin M.T. Emerging role of nitrite in human biology. Blood Cells Mol Dis 2004; 32(3): 423-429, https://doi.org/10.1016/j. bcmd.2004.02.002.

19. Eliseeva T.I., Kulpina Yu.S., Soodaeva S.K., Kubysheva N.I. Content of the nitrogen oxide metabolites in a condensate of exhaling air in children with a bronchial asthma control different level. Sovremennye tehnologii $v$ medicine 2010; 4: 42-47.

20. Kubysheva N., Soodaeva S., Postnikova L., Novikov V., Maksimova A., Chuchalin A. Associations between indicators of nitrosative stress and levels of soluble HLA-I, CD95 molecules in patients with COPD. COPD 2014; 11(6): 639-644, https:// doi.org/10.3109/15412555.2014.898042.

21. Lisitsa A.V., Soodaeva S.K., Klimanov I.A., Chuchalin A.G. Changes of oxidative stress parameters in patients with exacerbation of asthma under therapy with inhaled liposomal drugs. Russian Pulmonology 2010; 1: 74-79.

22. Mamaeva M.E., Alyasova A.V., Shumilova S.V., Kazatskaya Zh.A., Khazov M.V., Churkina N.N., Novikov V.V. Prognostic value of blood serum content of soluble CD50 and CD54 molecules in patients with uterine and cervical cancer. Sovremennye tehnologii $v$ medicine 2015; 7(4): 141-146, https://doi.org/10.17691/stm2015.7.4.19.

23. Schmal H., Czermak B.J., Lentsch A.B., Bless N.M., Beck-Schimmer B., Friedl H.P., Ward P.A. Soluble ICAM-1 activates lung macrophages and enhances lung injury. J Immunol 1998; 161(7): 3685-3693.

24. Zhang X., Wang L., Zhang H., Guo D., Zhao J., Qiao Z., Qiao J. The effects of cigarette smoke extract on the endothelial production of soluble intercellular adhesion molecule-1 are mediated through macrophages, possibly by inducing TNF-alpha release. Methods Find Exp Clin Pharmacol 2002; 24(5): 261-265, https://doi.org/10.1358/ mf.2002.24.5.802302.

25. Togo S., Holz O., Liu X., Sugiura H., Kamio K., Wang X., Kawasaki S., Ahn Y., Fredriksson K., Skold C.M., Mueller K.C. Branscheid D., Welker L., Watz H., Magnussen H., Rennard S.I. Lung fibroblast repair functions in patients with chronic obstructive pulmonary disease are altered by multiple mechanisms. Am J Respir Crit Care Med 2008; 178(3): 248260, https://doi.org/10.1164/rccm.200706-929oc.

26. Leeuwenberg J.F., Smeets E.F., Neefjes J.J., Shaffer M.A., Cinek T., Jeunhomme T.M., Ahern T.J., Buurman W.A. E-selectin and intercellular adhesion molecule-1 are released by activated human endothelial cells in vitro. Immunology 1992; 77(4): 543-549.

27. Zandvoort A., van der Geld Y.M., Jonker M.R., Noordhoek J.A., Vos J.T., Wesseling J., Kauffman H.F., Timens W., Postma D.S. High ICAM-1 gene expression in pulmonary fibroblasts of COPD patients: a reflection of an enhanced immunological function. Eur Respir J 2006; 28(1): 113-122, https://doi.org/10.1183/09031936.06.00116205.
28. Madjdpour C., Jewell U.R., Kneller S., Ziegler U., Schwendener R., Booy C., Kläusli L., Pasch T., Schimmer R.C., Beck-Schimmer B. Decreased alveolar oxygen induces lung inflammation. Am J Physiol Lung Cell Mol Physiol 2003; 284(2): L360-L367, https://doi.org/10.1152/ ajplung.00158.2002.

29. Barnett C.C. Jr., Moore E.E., Moore F.A., Carl V.S., Biffl W.L. Soluble ICAM-1 (sICAM-1) PROvokes PMN elastase release. J Surg Res 1996; 63(1): 6-10, https://doi.org/10.1006/ jsre.1996.0213.

30. Spiropoulos K., Trakada G., Nikolaou E., Prodromakis E., Efremidis G., Pouli A., Koniavitou A. Endothelin-1 levels in the pathophysiology of chronic obstructive pulmonary disease and bronchial asthma. Respir Med 2003; 97(8): 983-989, https://doi. org/10.1016/s0954-6111(03)00129-x.

31. Shi-Wen X., Denton C.P., Dashwood M.R., Holmes A.M., Bou-Gharios G., Pearson J.D., Black C.M., Abraham D.J. Fibroblast matrix gene expression and connective tissue remodeling: role of endothelin-1. J Invest Dermatol 2001; 116(3): 417-425, https://doi.org/10.1046/ j.1523-1747.2001.01256.x.

32. Abraham D. Role of endothelin in lung fibrosis. Eur Respir Rev 2008; 17(109): 145-150, https://doi. org/10.1183/09059180.00010907.

33. Teder P., Noble P.W. A cytokine reborn? Endothelin-1 in pulmonary inflammation and fibrosis. Am J Respir Cell Mol Biol 2000; 23(1): 7-10, https://doi.org/10.1165/ajrcmb.23.1.f192.

34. Dinakar C., Malur A., Raychaudhuri B., Buhrow L.T., Melton A.L., Kavuru M.S., Thomassen M.J. Differential regulation of human blood monocyte and alveolar macrophage inflammatory cytokine production by nitric oxide. Ann Allergy Asthma Immunol 1999; 82(2): 217-222, https://doi. org/10.1016/s1081-1206(10)62600-2.

35. Folkerts G., Kloek J., Muijsers R.B., Nijkamp F.P. Reactive nitrogen and oxygen species in airway inflammation. Eur J Pharmacol 2001; 429(1-3): 251-262, https://doi. org/10.1016/s0014-2999(01)01324-3.

36. Krishna M.T., Chauhan A.J., Frew A.J., Holgate S.T. Toxicological mechanisms underlying oxidant pollutant-induced airway injury. Rev Environ Health 1998; 13(1-2): 59-71.

37. Morrison D., Rahman I., Lannan S., MacNee W. Epithelial permeability, inflammation, and oxidant stress in the air spaces of smokers. Am J Respir Crit Care Med 1999; 159(2): 473-479, https://doi.org/10.1164/ajrccm.159.2.9804080.

38. Clini E., Bianchi L., Pagani M., Ambrosino N. Endogenous nitric oxide in patients with stable COPD: correlates with severity of disease. Thorax 1998, 53(10): 881 883, https://doi.org/10.1136/thx.53.10.881.

39. Franciosi L.G., Page C.P., Celli B.R., Cazzola M., Walker M.J., Danhof M., Rabe K.F., Della Pasqua O.E. Markers of disease severity in chronic obstructive pulmonary disease. Pulm Pharmacol Ther 2006, 19(3): 189-199.

40. Woska J.R. Molecular comparison of soluble intercellular adhesion Molecule (sICAM)-1 and sICAM-3 binding to lymphocyte function-associated antigen-1. J Biol Chem 1998; 273(8): 4725-4733, https:/ldoi org/10.1074/jbc. 273.8.4725 